Article

\title{
A Comparative Study of Fouling and Bottom Ash from Woody Biomass Combustion in a Fixed-Bed Small-Scale Boiler and Evaluation of the Analytical Techniques Used
}

\author{
Lara Febrero *, Enrique Granada, David Patiño, Pablo Eguía and Araceli Regueiro \\ Industrial Engineering School, University of Vigo, Campus Lagoas-Marcosende, s/n, 36310 Vigo, \\ Spain; E-Mails: egranada@uvigo.es (E.G.); patinho@uvigo.es (D.P.); peguia@uvigo.es (P.E.); \\ aregueiro@uvigo.es (A.R.) \\ * Author to whom correspondence should be addressed; E-Mail: 1febrero@uvigo.es; \\ Tel.: +34-986-818-624.
}

Academic Editor: Susan Krumdieck

Received: 30 January 2015 / Accepted: 7 May 2015 / Published: 12 May 2015

\begin{abstract}
In this work, fouling and bottom ash were collected from a low-power boiler after wood pellet combustion and studied using several analytical techniques to characterize and compare samples from different areas and determine the suitability of the analysis techniques employed. TGA results indicated that the fouling contained a high amount of organic matter (70\%). The XRF and SEM-EDS measurements revealed that $\mathrm{Ca}$ and $\mathrm{K}$ are the main inorganic elements and exhibit clear tendency in the content of $\mathrm{Cl}$ that is negligible in the bottom ash and increased as it penetrated into the innermost layers of the fouling. Calcite, magnesia and silica appeared as the major crystalline phases in all the samples. However, the bottom ash was primarily comprised of calcium silicates. The $\mathrm{KCl}$ behaved identically to the $\mathrm{Cl}$, preferably appeared in the adhered fouling samples. This salt, which has a low melting point, condenses upon contact with the low temperature tube and played a crucial role in the early stages of fouling formation. XRD was the most useful technique applied, which provided a semi-quantitative determination of the crystalline phases. FTIR was proven to be inadequate for this type of sample. The XRF and SEM-EDS, techniques yield similar results despite being entirely different.
\end{abstract}

Keywords: biomass; combustion; fouling; bottom ash; analytical techniques 


\section{Introduction}

The growing awareness of environmental issues and the strong dependence on fossil fuels have caused an increase in the use of biomass as an energy source, especially for thermal applications. Combustion of biomass in boilers is its most widely used application [1]. However, biomass, as a solid fuel, generates a significant amount of ash. Some of the ash is retained in the boiler grate as bottom ash, some is released in the flue gas as fly ash and, the remaining amount forms deposits in the internal parts of the boiler, causing problems such as fouling, slagging and corrosion among others [2-6]. Fouling is defined as deposits that form in areas of the boiler that are subjected to convective heat exchange. Slagging is constituted of deposits that form principally on surfaces exposed to radiation. Corrosion is the deterioration of materials due to contact with its environment [7]. As a result of these problems, there is a loss of efficiency due to the reduction of the heat exchange, which results in an increase in the operational and maintenance costs. Therefore, fouling, slagging and corrosion are the main challenges faced by biomass combustion boilers, which are a subject of study for many researchers [4-6,8-14]. The main cause of the formation of these deposits resides in the chemical composition of the biomass used in the combustion. The presence of high amounts of alkali metals such as $\mathrm{K}$ and $\mathrm{Na}$, and large quantities of $\mathrm{Cl}, \mathrm{S}$ and $\mathrm{Si}$ are primarily responsible for these problems. [6,7,9,12,14-18]. Many researches have focused on minimizing or removing these problems using methods such as co-firing with other types of fuel, such as different coals [9-11,13,19-21] or blends of various biomass species [14,22], and the use of additives such as phosphoric acid [3], ammonium sulfate [19], kaolin [14], halloysite [23], titanium oxide [24], Ca-based additives [25] and others [26-28]. Therefore, the knowledge on the composition of the ash and fouling material is crucial to understand the mechanisms behind fouling formation and to provide a method to combat it. Consequently, a correct determination of the elements and compounds comprising the samples via proper analytical techniques is essential in the study of biomass fouling.

The work carried out involved the combustion of wood pellets in an experimental fixed-bed low-power boiler under controlled conditions. This experimental plant was built specifically for research purposes, facilitating the extraction of areas susceptible to fouling and allowing the possibility of controlling, modifying and registering many combustion parameters. Then, bottom ash from the grate and fouling samples generated in the heat exchanger surface were collected and subjected to exhaustive studies. Thermogravimetric Analyses (TGA) were performed to determine the amount of organic and inorganic matter in the samples. Elemental chemical analyses were performed using Organic Elemental Analysis, X-Ray Fluorescence Spectroscopy (XRF) and Scanning Electron Microscopy with Energy Dispersive X-ray Spectroscopy (SEM-EDS). Compounds were determined by X-Ray Diffraction Spectroscopy (XRD) and by Fourier Transform Infrared Spectrometry (FTIR). Hence, the main objectives of this research were to identify elements and compounds comprising the samples using different analytical techniques and thereby establish a pattern in the fouling formation mechanism, compare results from samples gathered in different areas of the boiler and the tube, and perform a critical evaluation of the analytical techniques used, looking for a compromise between the targets sought and the current technical limitations. 


\section{Experimental Section}

\subsection{Fuel, Facility and Samples}

As presented in Table 1, the fuel used was commercial wood pellets, which is one of the most widely used biomass fuels in thermal applications due to the low amount of ash deposited during combustion. The size of the wood pellet supplied in the combustions was $6 \mathrm{~mm}$ in diameter and $20 \mathrm{~mm}$ in length. The empirical formulae for the fuel from the ultimate analyses was $\mathrm{CH}_{1.573} \mathrm{O}_{0.731}$ in dry basis. The coalification diagram relates $\mathrm{O} / \mathrm{C}$ ratio with $\mathrm{H} / \mathrm{C}$ ratio, this diagram can be used to deduce the chemical structure of the fuel and some combustion and inorganic aspects [29].

Table 1. Fuel analysis and characterization.

\begin{tabular}{|c|c|}
\hline \multicolumn{2}{|c|}{ Proximate analysis (wt.\% of dry fuel) } \\
\hline Moisture & $6.85^{\mathrm{a}}$ \\
\hline Ash & 0.44 \\
\hline Volatile Matter & 73.54 \\
\hline Fixed Carbon & 26.02 \\
\hline \multicolumn{2}{|c|}{ Ultimate analysis (wt.\% of dry fuel) } \\
\hline $\mathrm{C}$ & 47.21 \\
\hline $\mathrm{H}$ & 6.19 \\
\hline $\mathrm{N}$ & 0.14 \\
\hline $\mathrm{O}$ & $46.02^{b}$ \\
\hline $\mathrm{S}$ & c \\
\hline \multicolumn{2}{|c|}{ Ash analysis (wt.\% of dry ash) } \\
\hline $\mathrm{Na}_{2} \mathrm{O}$ & 6.22 \\
\hline $\mathrm{MgO}$ & 10.36 \\
\hline $\mathrm{Al}_{2} \mathrm{O}_{3}$ & 7.74 \\
\hline $\mathrm{SiO}_{2}$ & 16.47 \\
\hline $\mathrm{P}_{2} \mathrm{O}_{5}$ & 6.98 \\
\hline $\mathrm{SO}_{3}$ & 4.25 \\
\hline $\mathrm{Cl}$ & 3.27 \\
\hline $\mathrm{K}_{2} \mathrm{O}$ & 14.29 \\
\hline $\mathrm{CaO}$ & 28.03 \\
\hline $\mathrm{MnO}$ & 1.31 \\
\hline $\mathrm{Fe}_{2} \mathrm{O}_{3}$ & 0.83 \\
\hline $\mathrm{ZnO}$ & 0.24 \\
\hline HHV $\left(M J \cdot \mathrm{kg}^{-1}\right)$ & 17.72 \\
\hline LHV $\left(\mathbf{M J} \cdot \mathrm{kg}^{-1}\right)$ & 16.28 \\
\hline
\end{tabular}

${ }^{a}$ moisture is presented as receive while the rest of the components are in dry basis; ${ }^{\mathrm{b}}$ oxygen is calculated by difference $(\mathrm{O} \%=100-\mathrm{C} \%-\mathrm{H} \%-\% \mathrm{~N}-\mathrm{Ash} \%) ;{ }^{\mathrm{c}}$ sulfur is below equipment detection limit $(\mathrm{DL}=0.30 \%)$.

The equipment detection limit for the rest of the elements is $10 \mathrm{ppm}$.

The experimental plant aims to simulate a fixed-bed low-power boiler of approximately 10-15 kWth. This facility has been presented in previous works published by this research group [30,31], and an overview of the layout is seen in Figure 1. Specifically, the combustor is made primarily of stainless steel. It is a square section burner with a $0.12 \mathrm{~m}$ side where the fuel is continuously fed into the 
under-bed. The burner grate is fixed and inclined. So, the bed depth in the burner region was about $90 \mathrm{~mm}$ in the largest side and $40 \mathrm{~mm}$ in the smaller side. The fuel bed temperature in a fixed-bed combustor can be as high as $1000{ }^{\circ} \mathrm{C}$ or $1200{ }^{\circ} \mathrm{C}$ [32,33]. For this work, three assays of $4 \mathrm{~h}$ of stable combustion with a supplied airflow of $20 \mathrm{~m}^{3} \mathrm{~h}^{-1}$ were performed. The distribution of the primary and secondary airflow is variable; however, in these tests it is set at $20 \%-80 \%$, respectively. The primary air is introduced inside the bed, whereas the secondary air inlet is placed $0.35 \mathrm{~m}$ over the bed surface. The deposition probe is a stainless steel tube cooled by water at a mean temperature of $60{ }^{\circ} \mathrm{C}$. The setup also permits the temperature to be modified. The flue gas temperature in this zone $(0.5 \mathrm{~m}$ over the bed $)$ varies but it is usually between $450{ }^{\circ} \mathrm{C}$ and $550{ }^{\circ} \mathrm{C}$. Flue gases circulate through the chimney to a dilution air system where the combustion gases are diluted and they reduce their temperature before releasing into the atmosphere. There is also the possibility to determine the flue gas composition using a gas analyzer placed $0.10 \mathrm{~m}$ over the water tube. Additionally, particulate matter is sampled $0.30 \mathrm{~m}$ above the water tube. Under these conditions, the average fuel flow is $0.45 \mathrm{~g} \mathrm{~s}^{-1}\left(0.03 \mathrm{~kg} \mathrm{~m}^{-2} \mathrm{~s}^{-1}\right)$. Knowing the total airflow rate and the cross-sectional area of the burner, the average velocity of the gases can be found out and it was $\mathrm{V}=0.39 \mathrm{~m} \cdot \mathrm{s}^{-1}$. The main combustion parameters that were employed in the experiments are listed in Table 2.

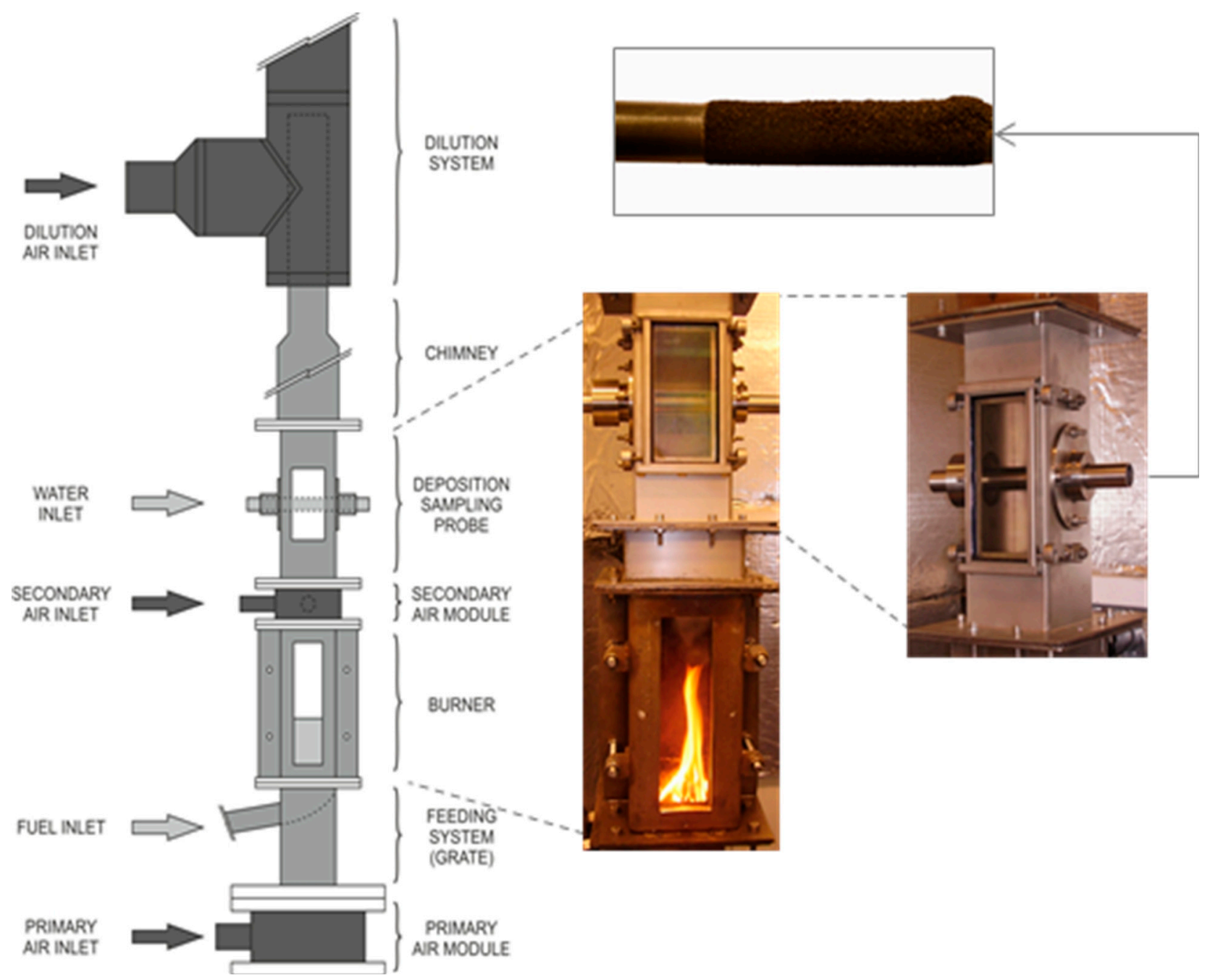

Figure 1. Experimental plant. 
Table 2. Combustion parameters for the tests in this work.

\begin{tabular}{cc}
\hline \multicolumn{2}{c}{ Combustion Parameters } \\
\hline Power generated & $10-15 \mathrm{kWth}$ \\
Stable combustion time & $4 \mathrm{~h}$ \\
Total airflow supplied & $20 \mathrm{~m}^{3} \mathrm{~h}^{-1}$ \\
Distribution of primary and secondary airflow & $20 \%-80 \%$ \\
Average water temperature & $\approx 60{ }^{\circ} \mathrm{C}$ \\
Average flue gas temperature & $450-550^{\circ} \mathrm{C}$ \\
Average mass fuel consumed & $0.45 \mathrm{~g} \mathrm{~s}^{-1}$ \\
\hline
\end{tabular}

The distribution of the primary and secondary air selection was based on experience and the information available in the literature. First, this distribution is very close to what is found in commercial low-power biomass boilers, typically 30\%-70\% [33-35]. Second, it is also known that a reduction in this ratio to include a higher content of secondary air can reduce NOx emissions, as well as fine particles [36]. Finally, we wish to achieve a confinement of the flame in the small dimensions of the burner, which can be accomplished by a reduction in the primary air ratio and an increase in the secondary air ratio. In fact, in grate combustors, the volume of the flame is very sensitive to the primary airflow and a small increase in this airflow causes a large change in the amount of fuel consumed. Otherwise, the dimensions of the burner are similar to a small scale biomass combustor, which is mainly used in domestic applications and represents an important contribution to the overall biomass heat production. These units tend to be small and eventually, in several commercial boilers, the heat exchanger is moved very close to the combustion. Due to this, the burnout distance or time is minimal. In fact, sometimes the flame quenches within the water tubes [37].

Three identical combustion processes were examined setting the same combustion parameters, i.e., temperatures of gases and water, airflow, primary and secondary airflow distribution, duration of the experiments and fuel consumed, and three samples were collected from each of the experiments. Bottom ash was gathered from the grate, and fouling samples were gathered from two zones within the tube. "Deposited fouling" corresponds to the most superficial layer of the fouling and is collected by shaking the tube, and "adhered fouling" corresponds to the innermost layer of fouling and adheres to the water-tube so that it must be unstuck from the tube. It corresponds to the initial layer of fouling formation. Table 3 describes the identification of the samples.

Table 3. Identification of the samples collected from the combustions performed.

\begin{tabular}{lccc}
\hline & Bottom Ash & Deposited Fouling & Adhered Fouling \\
\hline Combustion 1 & S1-B & S1-D & S1-A \\
Combustion 2 & S2-B & S2-D & S2-A \\
Combustion 3 & S3-B & S3-D & S3-A \\
\hline
\end{tabular}

In each of the experiments, approximately 5 grams of bottom ash was collected, which was enough to perform all the subsequent analyses. The amount of deposited fouling was also sufficient. However, the amount of adhered fouling collected from the tube is scarce (Table 4). Therefore, in the subsequent analyses, it was necessary to mix equal samples of adhered fouling from the three combustions, as explained in Section 2.2. 
Table 4. Amounts of the fouling samples gathered from each of the experiments.

\begin{tabular}{lcc}
\hline & Deposited Fouling (g) & Adhered Fouling (g) \\
\hline Combustion 1 & 0.42 & 0.12 \\
Combustion 2 & 0.41 & 0.08 \\
Combustion 3 & 0.37 & 0.10 \\
\hline
\end{tabular}

\subsection{Analytical Techniques}

\subsubsection{Thermal Analysis}

The thermal analyses were performedin aLabsys TG-DTA/DSC thermogravimeter from SETARAM Instrumentation. Thermogravimetric Analysis (TGA) and Differential Scanning Calorimetry (DSC) were carried out simultaneously. Approximately $10 \mathrm{mg}$ of each sample was heated to $550{ }^{\circ} \mathrm{C}$ from ambient temperature with a dry air flow of $100 \mathrm{~mL} \mathrm{~min}^{-1}$ and a heating rate of $30{ }^{\circ} \mathrm{C} \mathrm{min}{ }^{-1}$. This temperature was maintained over $2000 \mathrm{~s}$ until mass stabilization ocurred to oxidize all of the organic matter. The thermograms showed the effect of time, temperature, mass loss and heat flow from each analysis. All samples collected were subjected to the thermal program described above.

\subsubsection{Chemical Analysis}

Organic Elemental Analysis. A Fisons Carlo Erba EA1108 microanalyzer was used to determine the total content of $\mathrm{C}, \mathrm{H}, \mathrm{N}$, and $\mathrm{S}$ in the samples. This device has a measurement range from $100 \mathrm{ppm}$ to $100 \%$, with a detection limit of $10 \mathrm{ppm}$ for $\mathrm{C}, \mathrm{H}$ and $\mathrm{N}$. The equipment detection limit for $\mathrm{S}$ is $0.30 \%$. It was applied to each bottom ash and deposited fouling samples and the mixture of the three adhered fouling samples.

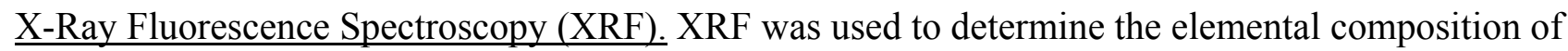
the samples. The equipment used was a Siemens SR3000 that can detect 78 elements with higher atomic numbers than that of $\mathrm{B}$, excluding $\mathrm{H}, \mathrm{Li}, \mathrm{Pm}, \mathrm{Tc}, \mathrm{Po}$, At and noble gases. The X-ray generator operates at a voltage between 20 and $60 \mathrm{kV}$ and a current of 5-100 mA. Each of the bottom ash, deposited fouling and mixed adhered fouling samples were subjected to XRF analyses.

Scanning Electron Microscopy with Energy Dispersive X-Ray Spectroscopy (SEM-EDS). A Philips XL 30 with EDAX was employed to obtain elemental chemical compositions, as well as microscopic images of the samples. The microscope has a resolution of $3.5 \mathrm{~nm}$, an accelerating voltage of $0.2-30 \mathrm{kV}$ and enlargement from 10-200,000×. All the samples were submitted for microanalysis of a representative area, they were prepared on circular supports of $12.5 \mathrm{~mm}$ diameter over carbon stickers. The working distance (WD) was approximately $10 \mathrm{~mm}$ and the dead time (DT\%) was kept under 30\% for all the experiments. Additional analyses of some specific points were performed to discern the composition of certain particles in the samples.

Fourier Transform Infrared Spectrometry (FTIR). After the thermal analysis, in which all the organic matter was oxidized, the remnants were used to manufacture a solid potassium bromide (KBr) pellet with the ratio of approximately $1 \%$ of sample and $99 \%$ of $\mathrm{KBr}$. A Varian 640 -IR spectrometer was employed. A spectrum was acquired every $15 \mathrm{~s}$ for $1 \mathrm{~min}$, using a resolution of $4 \mathrm{~cm}^{-1}$. FTIR spectrometry was applied to every sample collected. 


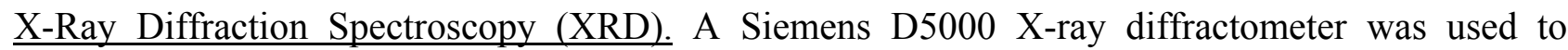
determine the crystalline phases and operated with a method of $\theta-2 \theta$. As in XRF, each sample of bottom ash, deposited fouling and mixed adhered fouling samples was submitted for XRD analysis.

\section{Results and Discussion}

\subsection{Thermal Results}

The TGA curves showed an initial mass loss due to the loss of moisture. Next, the curves exhibited greater mass loss in the temperature range of $350{ }^{\circ} \mathrm{C}-550{ }^{\circ} \mathrm{C}$, which indicated the unburned organic matter of the samples and, finally, the remaining mass corresponded to the inorganic material contained in the samples (Figure 2). The DSC curves corroborated these results, showing the endothermic effect of the sample drying, and the highly exothermic effect of the oxidation of the organic matter (Figure 2).

(a)

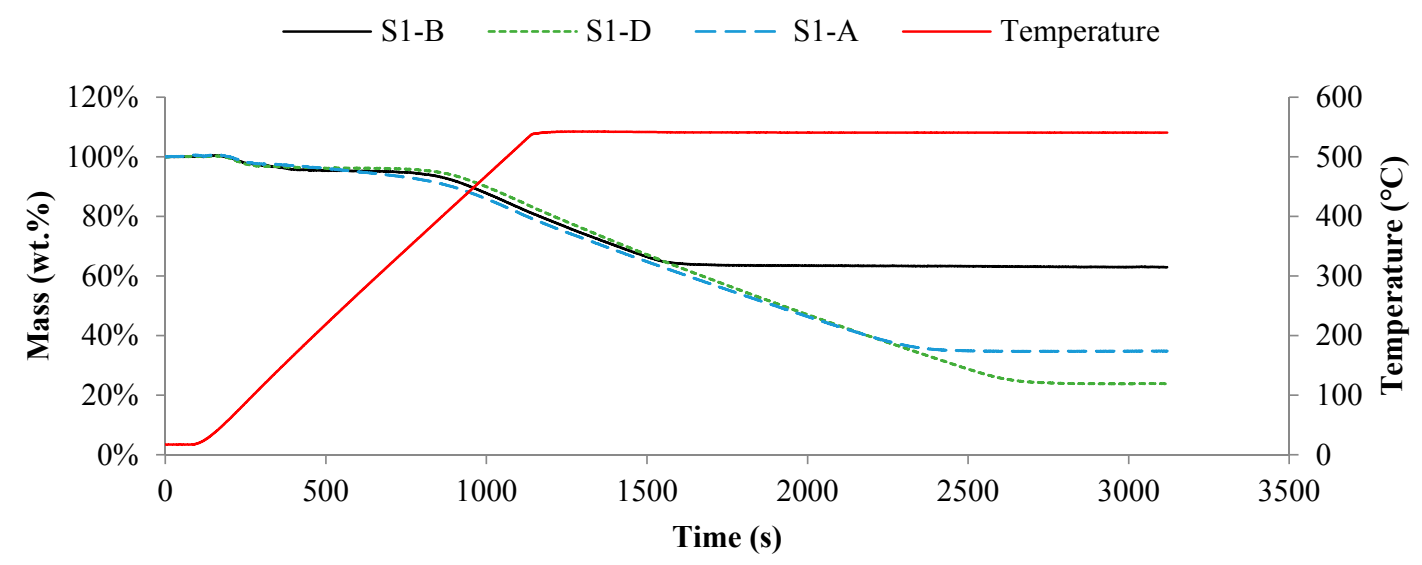

(b)

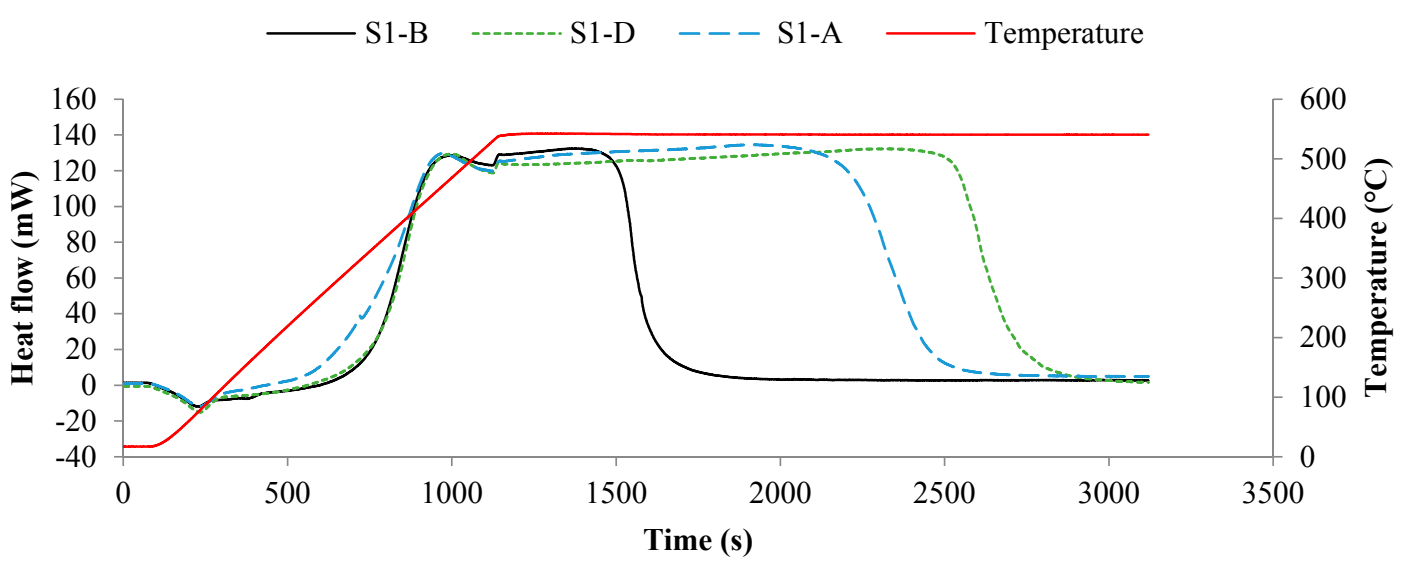

Figure 2. Thermogravimetric Analysis (TGA) (a) and Differential Scanning Calorimetry (DSC) (b) curves of samples S1-B, S1-D and S1-A.

Figure 3 shows the average organic and inorganic matter contents of the tube fouling and bottom ash on a dry basis. The considerable amount of organic matter in the bottom ash was mainly due to a transient 
shutdown. After $4 \mathrm{~h}$ of stable combustion, the burner was turned off and the fuel supply was stopped. However, during the shutdown process, some pellets remained unburned, contributing to the increase of the amount of organic matter in the bottom ash. Figure 3 also shows that the highest amount of organic matter (i.e., combustible material) appeared in fouling samples. As expected, deposited and adhered fouling samples were thermally similar with only slight differences, but deposited fouling samples had a higher amount of organic matter. The amount of organic matter present in the tube fouling samples was mainly due to the proximity of the flame to the tube during combustion, and the small size of the equipment. As explained, this set up exhibits the greatest similarity to a commercial low-power boiler and permits reproducibility of the real conditions as closely as possible for the combustion conditions that were examined. However, the organic matter in the fouling samples can be due to other factors, such as an incomplete combustion that leads to unburnt carbon, the transient turn on and shut down of the combustion with low temperatures or the residence time of the particles. It is known that a long residence time favors combustion but an entrained particle has a limited time function of the supplied airflow. This time could be insufficient for the burnout of the particle leading to unburnt particles deposited over the tube.

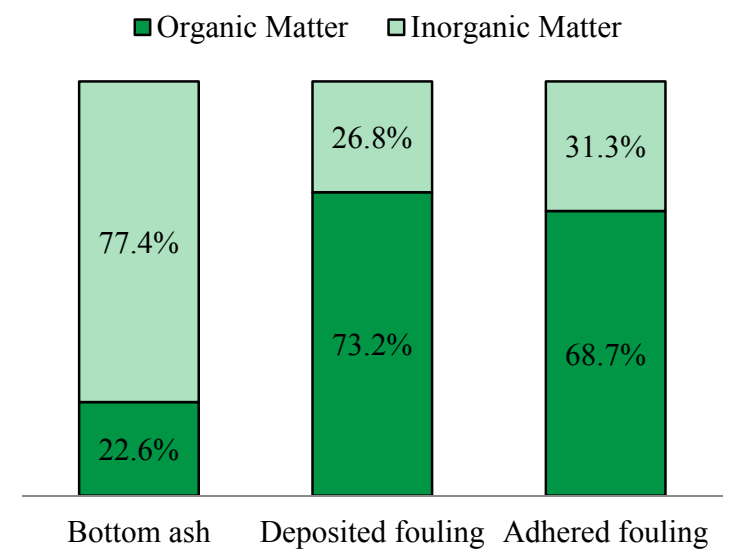

Figure 3. Average weight percentage of the organic and inorganic matter present in the different types of samples on a dry basis.

\subsection{Chemical Results}

\subsubsection{Organic Elemental Analysis}

The results presented in Table 5 corroborate those obtained in the thermal analysis. Samples of fouling from the tube showed a similar amount of carbon, which was slightly higher for the deposited fouling than for the adhered fouling. Apart from what has been stated, this may occur because the innermost layer of fouling is mainly formed by inorganic salts with a sticky nature. Once these salts condense, it is easier for unburned carbon particles to stick on impact. The tendency of the $\mathrm{N}$ is highlighted. During the combustion the $\mathrm{N}$ from the fuel was almost totally converted into gaseous $\mathrm{N}_{2}$, and $\mathrm{NO}_{\mathrm{x}}$, and only a small amount of $\mathrm{N}$ was incorporated in the ash, as observed in bottom ash. Most part of the $\mathrm{N}$ of the ash and fouling samples comes from unburned fuel. However, there was an increase of the amount of $\mathrm{N}$ in fouling samples, mostly in adhered fouling samples. This could be due to the loss of volatile $\mathrm{N}$ compounds during combustion and the lower temperatures of the tube surroundings. 
Table 5. Organic elemental analysis of the bottom ash and fouling. An average of the three samples was performed for the bottom ash and deposited fouling.

\begin{tabular}{cccc}
\hline Element & Bottom Ash & Deposited Fouling & Adhered Fouling \\
\hline$\% \mathbf{C}$ & 21.20 & 62.60 & 54.17 \\
$\% \mathbf{~ H}$ & 0.31 & 0.82 & 1.76 \\
$\% \mathbf{~ N}$ & 0.19 & 0.60 & 1.32 \\
$\% \mathbf{~ S}$ & $\mathrm{c}$ & $\mathrm{c}$ & $\mathrm{c}$ \\
\hline \multicolumn{4}{c}{${ }^{\mathrm{c}}$ sulfur is below equipment detection limit (DL $\left.=0.30 \%\right)}$.
\end{tabular}

\subsubsection{X-Ray Fluorescence Spectroscopy}

The ash content of the wood pellets was less than $0.5 \%$ and the $\mathrm{pH}$ of the ash was of 9.8 , indicating that it is basic. These pellets are dominated by alkali and alkaline earth metals as shown in Table 1. Apart from the analysis of the wood pellet ash, ash from the grate of the burner after combustion, which is also known as bottom ash, and fouling over the tube were studied. Comparing the samples of bottom ash and fouling with the inorganic elements from the wood pellets (Table 6 and Figure 4), the concentration of Fe in the wood pellet ash was much lower than in the samples collected, which indicated contamination from the experimental plant due to the detachment of the walls during combustion or contamination from the heat exchanger during sample collection.

The major elements in the bottom ash and fouling were determined to be $\mathrm{Ca}$ and $\mathrm{K}$. Moreover, Si and $\mathrm{Mg}$ were also found in large quantities. The bottom ash and deposited fouling were more similar in terms of their elemental compositions. The adhered fouling presented more contrast. Otherwise, the different behavior of the elements is indicated. On one hand, there were elements that decreased slightly in the adhered fouling or remained practically constant in all samples, including $\mathrm{Mg}, \mathrm{Al}, \mathrm{P}, \mathrm{Mn}$ or Fe. Most of these are non-volatile elements and, therefore, had a uniform behavior during the various stages of combustion and do not evaporate as easily as others. Other elements, such as $\mathrm{Si}, \mathrm{K}$ and $\mathrm{Ca}$, were mainly retained in the bottom ash and the lowest concentrations were found in the adhered fouling. Si and $\mathrm{Ca}$ were easily retained in the bed due to their non-volatile nature. Finally, $\mathrm{Na}, \mathrm{S}$ and $\mathrm{Cl}$ appeared in much greater proportions in the adhered fouling. This is thought to be due to the high volatility of these elements. They are easily volatilized during the combustion leading to a high mobility [38]. During combustion, the $\mathrm{Cl}$ contained in the biomass mainly forms gaseous $\mathrm{HCl}, \mathrm{Cl}_{2}$ or alkali chlorides such as $\mathrm{KCl}$ or $\mathrm{NaCl}$. Like $\mathrm{Cl}$, the $\mathrm{S}$ contained in the biomass mainly forms gaseous $\mathrm{SO}_{2}, \mathrm{SO}_{3}$, alkali sulfates and alkaline-earth sulfates [39]. Therefore, they volatilized in the initial stages of combustion and became part of the first layers of fouling. They increased in concentration as they penetrated into the innermost layers of the fouling. Particularly, $\mathrm{Cl}$ plays a role in transport, increasing the volatility of alkali metals [7] and facilitating the transfer of $\mathrm{K}$ to potassium chloride $(\mathrm{KCl})$. Some of the elements present in the samples are responsible for undesirable reactions during combustion, including $\mathrm{K}$ reacting with $\mathrm{Si}$ to form alkali silicates with a low melting temperature and $\mathrm{K}$ also reacting with $\mathrm{Cl}$ and $\mathrm{S}$ to form alkali sulfates and chlorides, which readily deposit on the surfaces of boilers [40]. 
Table 6. Inorganic elements determined using XRF for the oxide forms in wt.\% and normalized to 100\%. WP-Wood pellet inorganic elements.

\begin{tabular}{|c|c|c|c|c|c|c|c|c|c|c|c|c|c|c|c|c|c|c|c|}
\hline & $\mathrm{Na}_{2} \mathrm{O}$ & MgO & $\mathrm{Al}_{2} \mathrm{O}_{3}$ & $\mathrm{SiO}_{2}$ & $\mathrm{P}_{2} \mathrm{O}_{5}$ & $\mathrm{SO}_{3}$ & $\mathrm{Cl}$ & $\mathbf{K}_{2} \mathrm{O}$ & $\mathrm{CaO}$ & $\mathrm{TiO}_{2}$ & $\mathrm{Cr}_{2} \mathrm{O}_{3}$ & $\mathrm{MnO}$ & $\mathrm{Fe}_{2} \mathrm{O}_{3}$ & $\mathrm{NiO}$ & $\mathrm{CuO}$ & $\mathrm{ZnO}$ & $\mathbf{R} \mathbf{b}_{2} \mathbf{O}$ & SrO & $\mathrm{BaO}$ \\
\hline WP & 6.22 & 10.36 & 7.74 & 16.47 & 6.98 & 4.25 & 3.27 & 14.29 & 28.03 & 0.00 & 0.00 & 1.31 & 0.83 & 0.00 & 0.00 & 0.24 & 0.00 & 0.00 & 0.00 \\
\hline S1-B & 2.61 & 13.34 & 3.48 & 11.84 & 4.93 & 3.09 & 0.57 & 19.59 & 29.95 & 0.16 & 0.23 & 1.88 & 7.59 & 0.13 & 0.04 & 0.14 & 0.02 & 0.07 & 0.34 \\
\hline S2-B & 2.59 & 10.07 & 4.73 & 23.93 & 4.26 & 1.58 & 0.08 & 19.64 & 25.34 & 0.21 & 0.12 & 1.60 & 5.25 & 0.06 & 0.05 & 0.02 & 0.04 & 0.08 & 0.35 \\
\hline S3-B & 2.53 & 11.20 & 4.28 & 19.57 & 4.58 & 1.84 & 0.23 & 19.82 & 27.11 & 0.21 & 0.21 & 1.88 & 5.72 & 0.13 & 0.06 & 0.07 & 0.06 & 0.18 & 0.30 \\
\hline S1-D & 3.22 & 14.20 & 4.80 & 17.91 & 4.25 & 8.15 & 2.58 & 12.69 & 24.06 & 0.16 & 0.42 & 1.03 & 5.83 & 0.23 & 0.03 & 0.13 & 0.00 & 0.03 & 0.29 \\
\hline S2-D & 2.91 & 12.53 & 3.78 & 13.70 & 4.56 & 9.90 & 4.63 & 14.09 & 26.15 & 0.16 & 0.39 & 1.10 & 5.38 & 0.18 & 0.05 & 0.14 & 0.02 & 0.02 & 0.30 \\
\hline S3-D & 2.62 & 10.21 & 3.55 & 13.37 & 4.40 & 7.95 & 2.62 & 17.74 & 28.40 & 0.15 & 0.36 & 1.54 & 6.27 & 0.18 & 0.03 & 0.18 & 0.03 & 0.06 & 0.33 \\
\hline S1-S2-S3-A & 9.36 & 11.49 & 3.32 & 10.98 & 3.11 & 15.77 & 12.38 & 12.08 & 15.56 & 0.09 & 0.30 & 0.61 & 4.38 & 0.14 & 0.02 & 0.23 & 0.00 & 0.02 & 0.14 \\
\hline
\end{tabular}

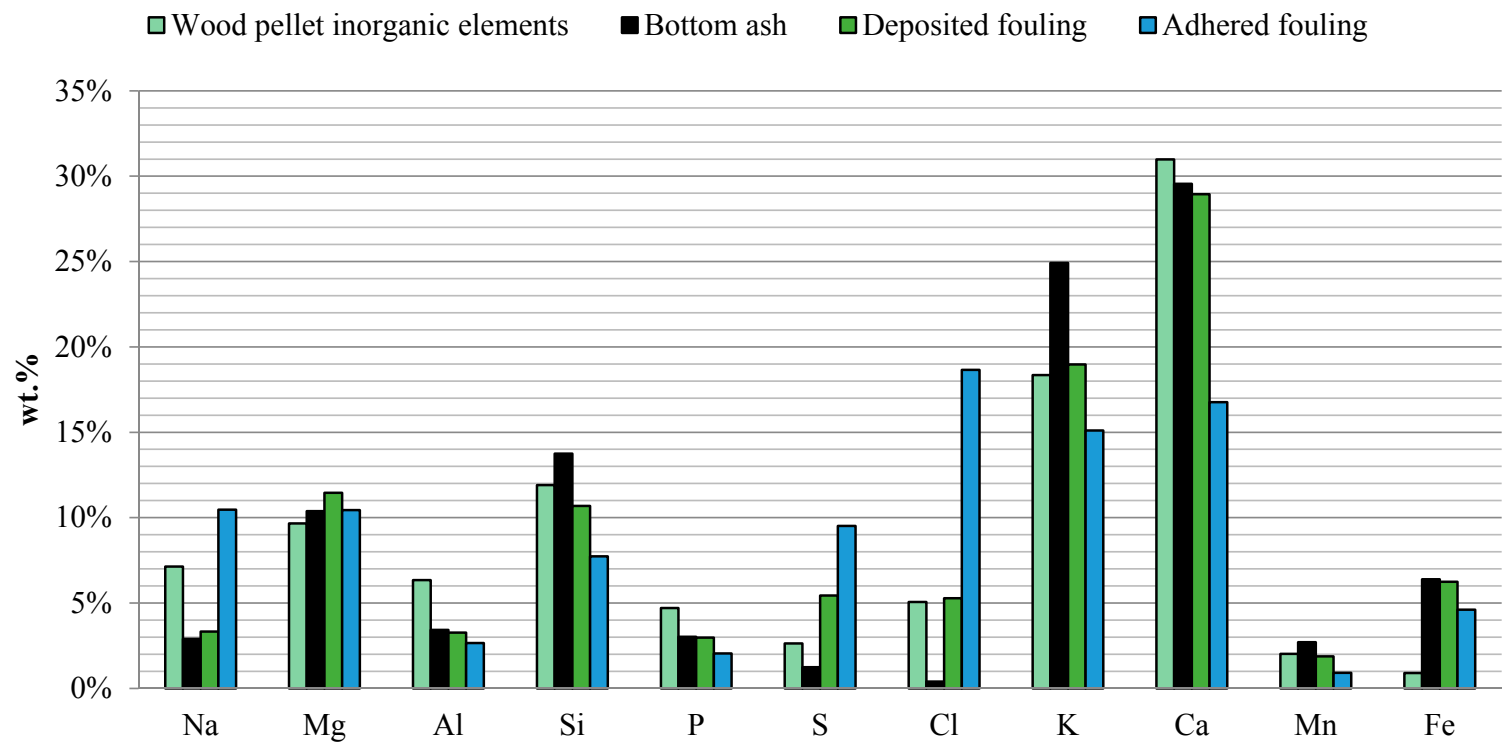

Figure 4. Inorganic elements in the wood pellets, bottom ash and fouling determined from XRF in terms of wt.\%, removing trace elements, presenting data in elemental form and averaging samples from the same zone. 


\subsubsection{Scanning Electron Microscopy with Energy Dispersive X-Ray Spectroscopy (SEM-EDS)}

SEM-EDS was applied to analyze all the samples by combining a visual image with the quantification of the elements. Figure 5 shows the areas where the microanalyses were performed. After a visual analysis using the microscope and taking into account the magnification of the images, it was found that the particle size was larger for bottom ash than for fouling on the tube. The samples contained mainly carbon. However, the carbon examined by EDS analysis should not be taken as-is, because the samples were deposited on carbon stickers. The next most abundant element detected was oxygen.
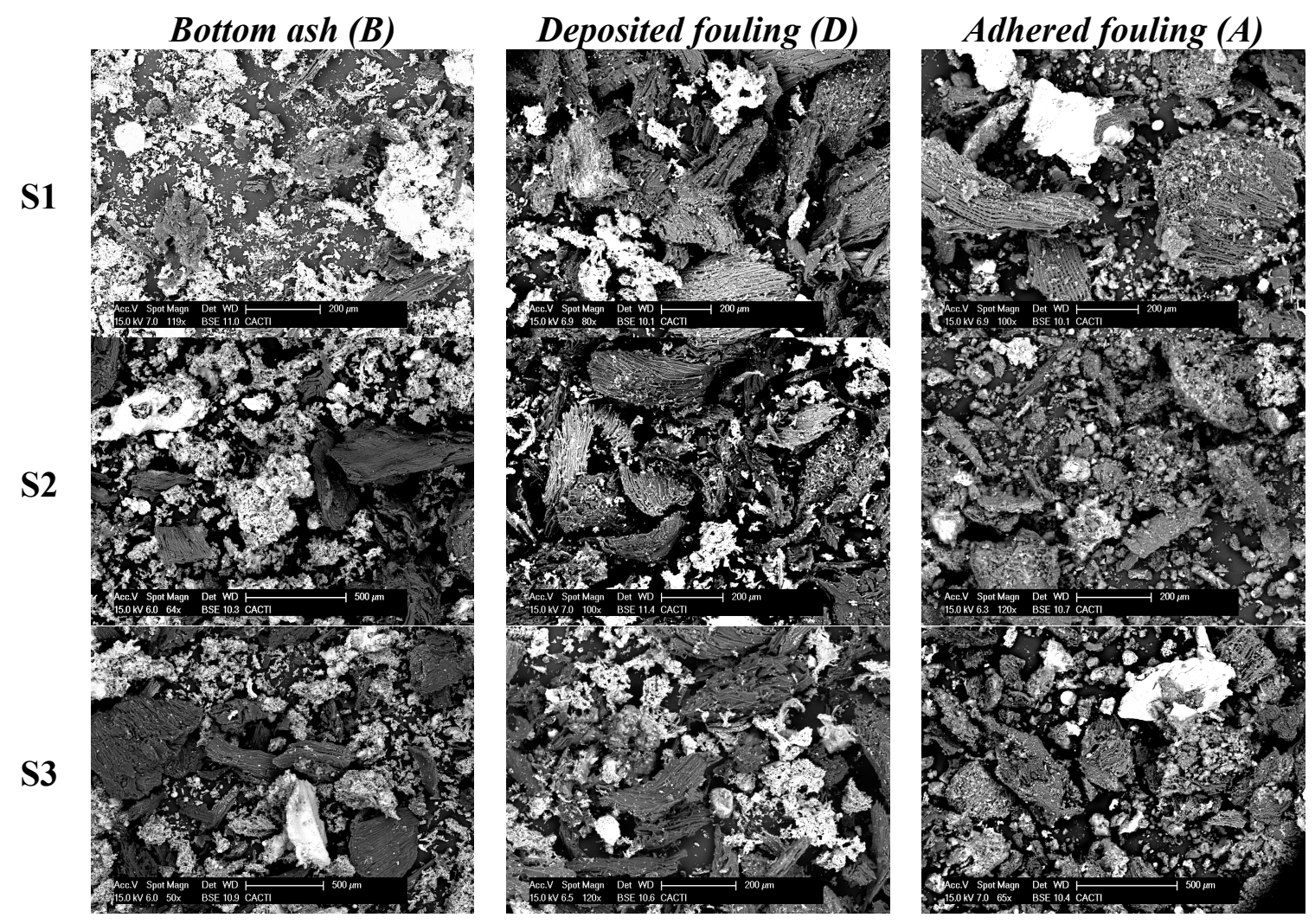

Figure 5. SEM imaging of the areas where the microanalysis was performed.

Figure 6 shows the inorganic elements resulting from the previous microanalysis and removing the carbon and oxygen to observe the differences between them. As with XRF, it was observed that Ca and $\mathrm{K}$ are the major elements. $\mathrm{Mg}$ and Fe were also found in large quantities. Furthermore, $\mathrm{S}$ and, over all, $\mathrm{Cl}$ exhibited the same trends observed in XRF results. The $\mathrm{Cl}$ percentage in the bottom ash samples was negligible and the highest percentage of chlorine appeared in the internal fouling.

Moreover, using SEM-EDS technique, it is possible to discriminate small areas or points of interest (Figure 7). Dark and fibrous particles were mainly formed by carbon and oxygen, and primarily originated from unburned biomass. In addition, the most clear and bright particles are mainly composed of inorganic matter, particularly alkali and alkaline earth metals, as well as Fe and Si. 


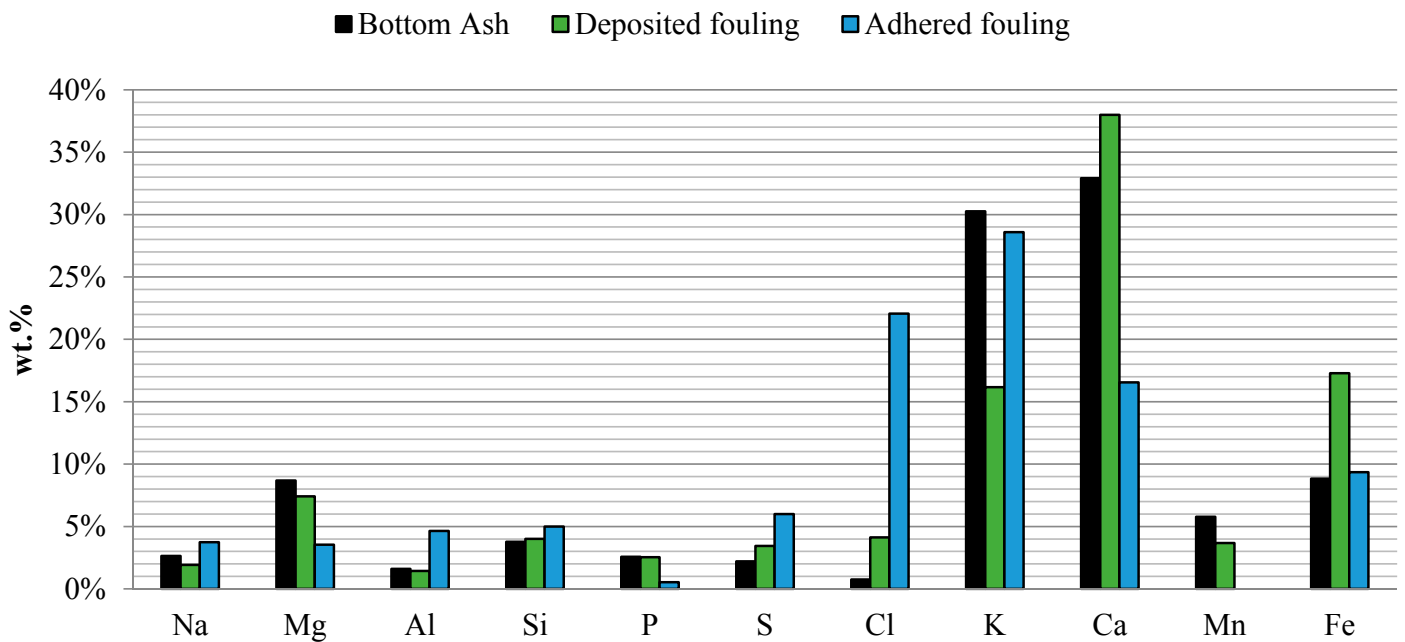

Figure 6. Inorganic elements (wt.\%) present in the bottom ash and fouling samples determined using SEM-EDS. $\mathrm{C}$ and $\mathrm{O}$ are removed to distinguish tendencies; the rest of the inorganic elements were normalized to $100 \%$.

\begin{tabular}{|c|c|c|c|c|}
\hline & & 1 & & 3 \\
\hline & C & 91.40 & C & 76.58 \\
\hline & $\mathbf{O}$ & 6.10 & $\mathbf{O}$ & 15.90 \\
\hline 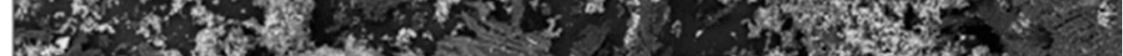 & $\mathbf{M g}$ & 0.16 & Mg & 0.30 \\
\hline 85 & $\mathbf{K}$ & 0.53 & $\mathbf{K}$ & 6.06 \\
\hline$x=0$ & $\mathrm{Ca}$ & 0.53 & $\mathbf{F e}$ & 1.15 \\
\hline 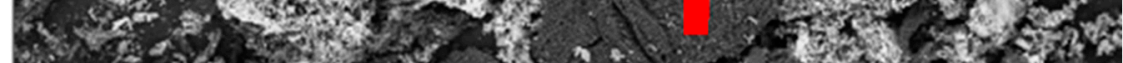 & $\mathbf{F e}$ & 1.29 & & \\
\hline & & 2 & & 4 \\
\hline & C & 11.77 & C & 12.95 \\
\hline & $\mathbf{O}$ & 35.47 & O & 32.35 \\
\hline & $\mathbf{N a}$ & 1.11 & $\mathbf{N a}$ & 2.39 \\
\hline & Mg & 3.91 & Mg & 4.28 \\
\hline & Al & 1.26 & Al & 0.70 \\
\hline & $\mathbf{S i}$ & 1.79 & $\mathbf{S i}$ & 10.84 \\
\hline & $\mathbf{P}$ & 1.11 & $\mathbf{P}$ & 1.22 \\
\hline 3 & $\mathbf{K}$ & 3.06 & $\mathbf{S}$ & 0.31 \\
\hline 血 & $\mathrm{Ca}$ & 19.56 & K & 6.97 \\
\hline & $\mathrm{Mn}$ & 2.26 & $\mathbf{C a}$ & 16.23 \\
\hline & $\mathbf{F e}$ & 17.80 & Mn & 2.57 \\
\hline & $\mathrm{Co}$ & 0.90 & $\mathbf{F e}$ & 9.21 \\
\hline
\end{tabular}

Figure 7. SEM-EDS applied to various points and areas of sample S1-B. The results are given in wt.\%. 


\subsubsection{Comparison between Elemental Techniques}

Comparing the XRF and SEM-EDS results, we observe that they exhibited comparable results, as shown in Figure 8. It must be taking into account that XRF is a more accurate technique than SEM-EDS at quantifying the elements. XRF is based on the detection of secondary or fluorescent emission generated by exciting the sample with a source of X-ray radiation. Otherwise, SEM-EDS is based on the detection of the energy of secondary or backscattered electrons when the sample is scanned with a source of X-ray radiation. SEM-EDS presents a microanalysis of a very small superficial area of the sample. Furthermore, the required sample size is much smaller for SEM-EDS, requiring only a few micrograms. However, for XRF, sample masses on the order of grams are required. Silicon is the element that presented more differences, appearing in higher quantities in the XRF for all the cases. Major elements were found in larger amounts using SEM-EDS, which is possibly derived from the precision and accuracy of the techniques.
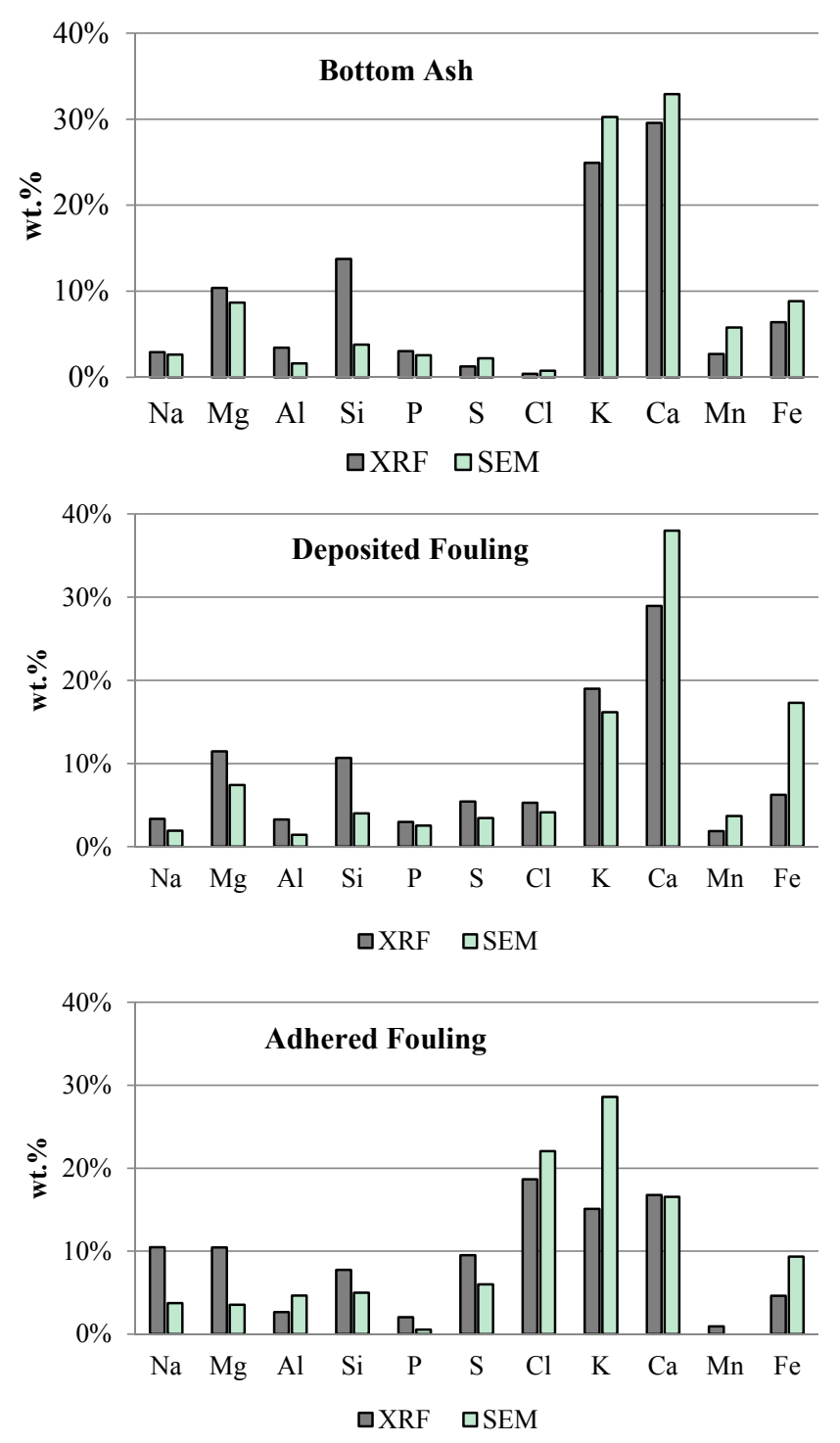

Figure 8. Comparison of inorganic elements in the bottom ash, deposited fouling and adhered fouling using XRF and SEM-EDS. 


\subsubsection{Fourier Transform Infrared Spectrometry (FTIR)}

Infrared absorption spectroscopy is used primarily to identify organic compounds, especially gases $[3,4,19,22]$. FTIR is not typically used for the determination of inorganic compounds, as these components vibrate at wavenumbers less than $400 \mathrm{~cm}^{-1}$. Therefore, the identification of inorganic solids with this device requires considerable interpretation, because the spectra are overlapped. The spectra of each sample were very similar, as shown in Figure 9, which means that they were formed by the same type of functional groups. All the analyzed spectra exhibited peaks at wavenumbers of $3400 \mathrm{~cm}^{-1}$ and $1600 \mathrm{~cm}^{-1}$ due to the moisture absorbed in the preparation of the potassium bromide pellets, as this compound is hygroscopic and there is moisture in the samples. The results indicated that calcium carbonate $\left(\mathrm{CaCO}_{3}\right)$ appeared in all the samples and has its strongest peak between $1495 \mathrm{~cm}^{-1}$ and $1410 \mathrm{~cm}^{-1}$ and a middle peak between $885 \mathrm{~cm}^{-1}$ and $870 \mathrm{~cm}^{-1}$. Some samples appeared to contain sulfates because they exhibit a characteristic peak in the wavenumber between $1200 \mathrm{~cm}^{-1}$ and $1140 \mathrm{~cm}^{-1}$. However, no sulfates were found using XRD, as observed in Figure 10. Furthermore, there were indications of the presence of silicon dioxide $\left(\mathrm{SiO}_{2}\right)$, which has a characteristic peak between $1100 \mathrm{~cm}^{-1}$ and $1075 \mathrm{~cm}^{-1}$.

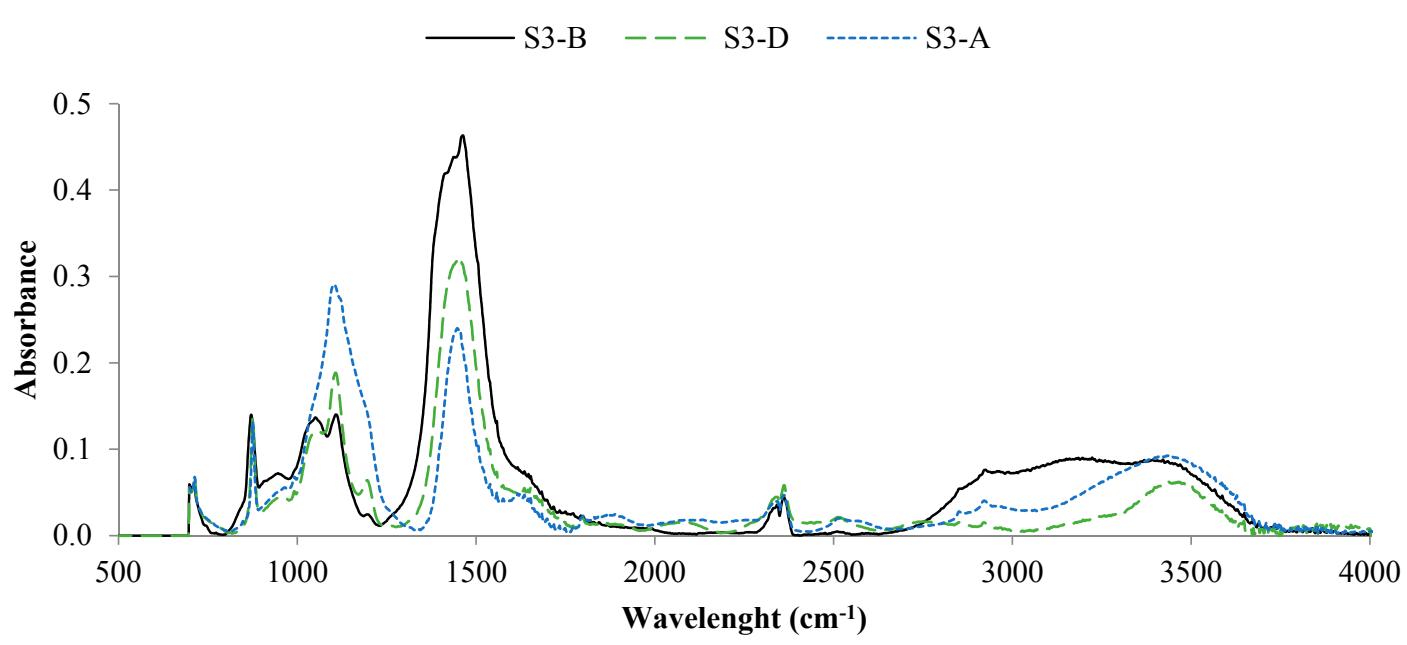

Figure 9. Comparison of the FTIR spectra of the samples S3-B, S3-D and S3-A.

Hence, this technique is not suitable for this type of analysis, as it relies too heavily on the judgment and interpretation of the technician. Therefore, inorganic solids can vibrate outside this range, and due to the heterogeneity of the samples, overlapping is inevitable. Moreover, spectrum peaks are characteristic of a bond and obviously many inorganic compounds share bonds, which further hinders the interpretation.

\subsubsection{X-Ray Diffraction Spectroscopy (XRD)}

Figure 10 shows the crystalline phases present in the samples. Some compounds such as silica $\left(\mathrm{SiO}_{2}\right)$, calcite $\left(\mathrm{CaCO}_{3}\right)$, magnesia $(\mathrm{MgO})$ and magnetite $\left(\mathrm{Fe}_{3} \mathrm{O}_{4}\right)$ appeared in all the areas. This was corroborated from the results obtained using XRF and SEM-EDS, which showed $\mathrm{Ca}$ and then $\mathrm{Mg}$, Si and Fe were the main elements. It was noteworthy that the behavior of potassium chloride $(\mathrm{KCl})$ showed the same 
tendency as $\mathrm{Cl}$. The elements $\mathrm{K}$ and $\mathrm{Cl}$ are primarily in the form of water soluble inorganic salts as oxides, nitrates, chlorides, etc. As stated before, during combustion, the $\mathrm{Cl}$ contained in the biomass mainly forms gaseous $\mathrm{HCl}, \mathrm{Cl}_{2}$ or alkali chlorides such as $\mathrm{KCl}[38,39]$. The $\mathrm{KCl}$ is characterized by its low melting point and by its sticky nature. Thus, when this compound encounters the low temperatures of the heat exchanger tube, it condenses and then, due to its sticky nature, the rest of particles released during combustion will be deposited on the tube and form the various fouling layers. Sulfur exhibited the same behavior. However, there was no detectable sulfur salt using XRD, as other researchers have identified [4,9]. Considering the amount of $\mathrm{K}, \mathrm{Cl}$ and $\mathrm{S}$ in the adhered fouling (Table 6 and Figure 4), the data suggest that $\mathrm{Cl}$ predominated over $\mathrm{S}$. Hence, $\mathrm{K}$ reacted completely with $\mathrm{Cl}$ and did not react with $\mathrm{S}$, which is why $\mathrm{KCl}$ was identified, but no $\mathrm{K}_{2} \mathrm{SO}_{4}$ was found. As stated, calcite was present in all the samples. This compound decomposes over the temperature range from $700{ }^{\circ} \mathrm{C}-900{ }^{\circ} \mathrm{C}$ in carbon dioxide $\left(\mathrm{CO}_{2}\right)$ and calcium oxide $(\mathrm{CaO})$. Then, from these temperatures, calcium oxide reacts with silica and other compounds to form silicates with calcium [31]. Based on the results from the XRD, this behavior is confirmed. Therefore, due to the high temperatures reached and especially in bottom ash, calcium silicates are the main compounds in these samples. However, the presence of calcite as a primary crystalline phase in all samples indicated that these high temperatures were not reached uniformly throughout the combustion burner. Although, the presence of calcite is expected in any case, as other authors have found [5] because the temperature non-uniformities are associated with not only the burner design, but also the fuel size and granulometry.

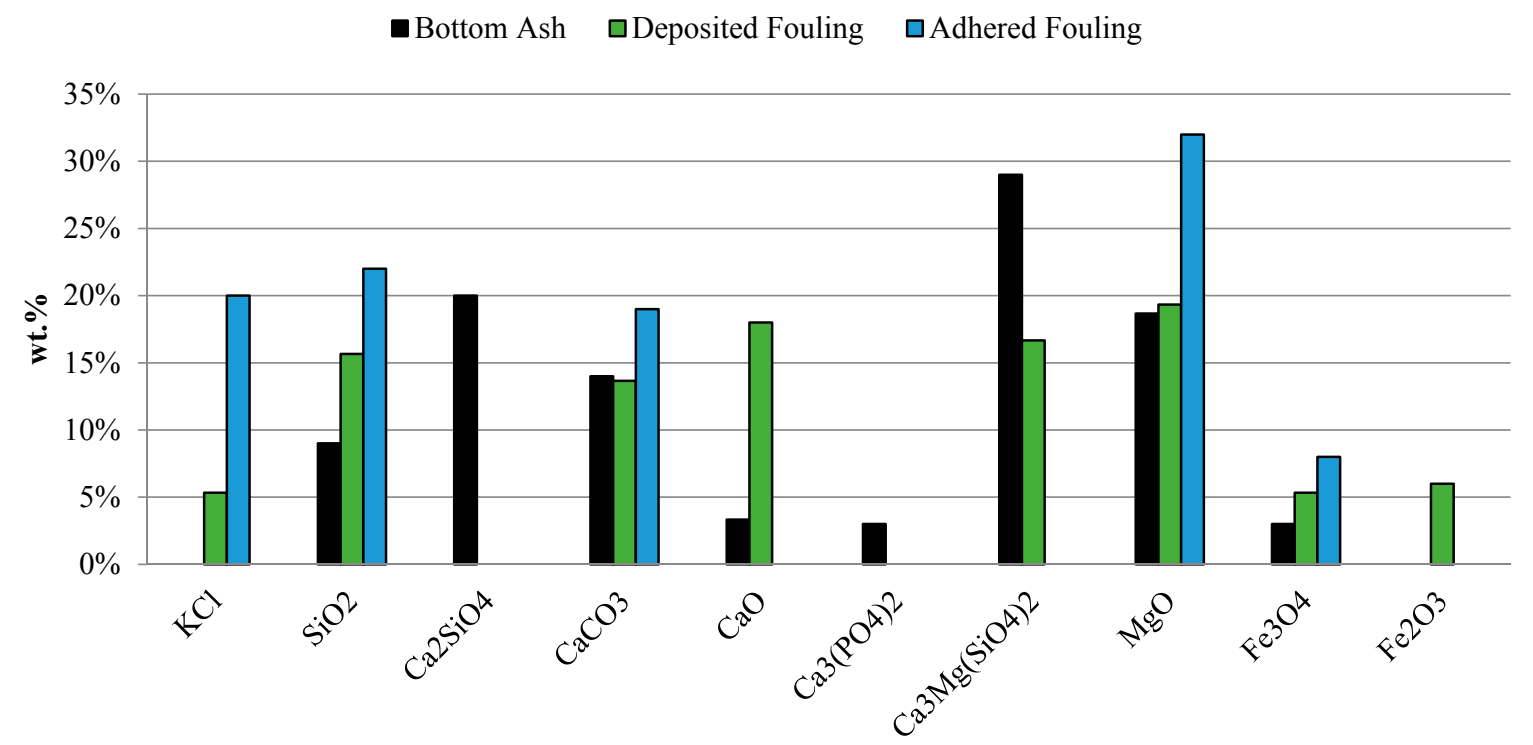

Figure 10. XRD results from the bottom ash, deposited and adhered fouling.

\section{Conclusions}

The thermal and organic elemental analyses revealed that the amount of organic matter remaining in the bottom ash was much lower than in the fouling samples. Remarkably, the bottom ash and deposited fouling exhibited similar concentrations of inorganic elements, and hence, the adhered fouling was the most different. Furthermore, the differences between fouling samples revealed distinct stages in the 
mechanism of fouling formation. $\mathrm{Ca}$ and $\mathrm{K}$ were the main inorganic elements found in the bottom ash and deposited fouling, followed by $\mathrm{Si}, \mathrm{Mg}$ and $\mathrm{Fe}$. Otherwise, the appearance of $\mathrm{Cl}$ in much higher concentrations in the adhered fouling samples, confirmed the volatile nature of this element and its transport role in the early stages of combustion. The results from XRD corroborated this behavior, and $\mathrm{KCl}$ appeared as the main crystalline phase in the adhered fouling. This compound was not found in the bottom ash but was observed in the deposited fouling and in a much greater concentration in the adhered fouling. It is a salt with a low melting point and a sticky nature and when in gaseous form, it comes into contact with the tube of the boiler remains stuck. Moreover, $\mathrm{Ca}$ and Si were identified as major inorganic elements. This was confirmed by finding carbonates, silica and silicates using the XRD. Furthermore, calcite, magnesia, and silica were key crystalline phases in all samples. Otherwise, the presence of silicates particularly at the bottom ash samples is indicative of the high temperatures reached during combustion.

The SEM-EDS technique enabled imaging and providing relevant microanalysis. This technique is complete, relatively fast and widely used. However, although the XRF requires larger amounts of the sample, it is more accurate. Both techniques, despite being entirely different techniques, seemed to yield similar results. More detailed studies on the precision and accuracy of both techniques are being conducted. Finally, the XRD allowed a semi-quantification of the crystalline phases. However, FTIR is not recommended for this purpose, as the determination of the solid inorganic compounds was ineffective and difficult to interpret due to the overlapping spectra.

The equipment used in this work can be compared to a commercial low-power biomass boiler with the significant advantage of having a deposition probe that can be easily extracted and the ability to vary and record a large number of parameters, such as supplied fuel ratio, air flow, air distribution, temperatures, etc. Additionally, the results are inevitably conditioned to experimental facilities and test parameters. The originality of this work resides in the combination of ash and fouling characterization in a versatile facility, which can vary combustion parameters and study their effect on the resulting deposits. The potential for this experimental facility is broad and includes the variation and registration of almost every combustion condition and the easy extraction of the probe. Therefore, further studies modifying the combustion parameters and feedstock are being carried out.

\section{Acknowledgments}

The authors acknowledge financial support from the project ENE2012-36405 of the Ministry of Economy and Competitiveness (Spain).

\section{Author Contributions}

Lara Febrero and Enrique Granada conceived, designed and conducted the research. David Patiño, Pablo Eguía and Araceli Regueiro provided experimental support and collaborated in the interpretation and analysis of data. Lara Febrero wrote the manuscript. All authors reviewed and approved the final manuscript.

\section{Conflicts of Interest}

The authors declare no conflict of interest. 


\section{References}

1. Saidur, R.; Abdelaziz, E.A.; Demirbas, A.; Hossain, M.S.; Mekhilef, S. A review on biomass as a fuel for boilers. Renew. Sustain. Energy Rev. 2011, 15, 2262-2289.

2. Demirbas, A. Potential applications of renewable energy sources, biomass combustion problems in boiler power systems and combustion related environmental issues. Progr. Energy Combust. Sci. 2005, 31, 171-192.

3. Grimm, A.; Skoglund, N.; Boström, D.; Boman, C.; Öhman, M. Influence of phosphorus on alkali distribution during combustion of logging residues and wheat straw in a bench-scale fluidized bed. Energy Fuels 2012, 26, 3012-3023.

4. Davidsson, K.O.; Åmand, L.E.; Leckner, B.; Kovacevik, B.; Svane, M.; Hagström, M.; Pettersson, J.B.C.; Petterson, J.; Asteman, H.; Svensson, J.E.; et al. Potassium, chlorine, and sulfur in ash, particles, deposits, and corrosion during wood combustion in a circulating fluidized-bed boiler. Energy Fuels 2007, 21, 71-81.

5. Szemmelveisz, K.; Szucs, I.; Palotás, Á.B.; Winkler, L.; Eddings, E.G. Examination of the combustion conditions of herbaceous biomass. Fuel Process. Technol. 2009, 90, 839-847.

6. Baxter, L.L.; Miles, T.R.; Miles, T.R., Jr.; Jenkins, B.M.; Milne, T.; Dayton, D.; Bryers, R.W.; Oden, L.L. The behavior of inorganic material in biomass-fired power boilers: Field and laboratory experiences. Fuel Process. Technol. 1998, 54, 47-78.

7. Khan, A.A.; de Jong, W.; Jansens, P.J.; Spliethoff, H. Biomass combustion in fluidized bed boilers: Potential problems and remedies. Fuel Process. Technol. 2009, 90, 21-50.

8. Darvell, L.I.; Jones, J.M.; Gudka, B.; Baxter, X.C.; Saddawi, A.; Williams, A.; Malmgren, A. Combustion properties of some power station biomass fuels. Fuel 2010, 89, 2881-2890.

9. Teixeira, P.; Lopes, H.; Gulyurtlu, I.; Lapa, N.; Abelha, P. Evaluation of slagging and fouling tendency during biomass co-firing with coal in a fluidized bed. Biomass Bioenergy 2012, 39, 192-203.

10. Hansen, L.A.; Frandsen, F.J.; Dam-Johansen, K.; Sørensen, H.S.; Skrifvars, B.J. Characterization of ashes and deposits from high-temperature coal-straw co-firing. Energy Fuels 1999, 13, 803-816.

11. Gogebakan, Z.; Gogebakan, Y.; Selçuk, N.; Selçuk, E. Investigation of ash deposition in a pilot-scale fluidized bed combustor co-firing biomass with lignite. Bioresour. Technol. 2009, 100, 1033-1036.

12. Li, L.; Yu, C.; Huang, F.; Bai, J.; Fang, M.; Luo, Z. Study on the deposits derived from a biomass circulating fluidized-bed boiler. Energy Fuels 2012, 26, 6008-6014.

13. Pronobis, M. The influence of biomass co-combustion on boiler fouling and efficiency. Fuel 2006, $85,474-480$.

14. Aho, M.; Silvennoinen, J. Preventing chlorine deposition on heat transfer surfaces with aluminium-silicon rich biomass residue and additive. Fuel 2004, 83, 1299-1305.

15. Vassilev, S.V.; Baxter, D.; Andersen, L.K.; Vassileva, C.G. An overview of the composition and application of biomass ash. Part 1. Phase-mineral and chemical composition and classification. Fuel 2013, 105, 40-76. 
16. Johansen, J.M.; Aho, M.; Paakkinen, K.; Taipale, R.; Egsgaard, H.; Jakobsen, J.G.; Frandsen, F.J.; Glarborg, $\mathrm{P}$. Release of $\mathrm{K}, \mathrm{Cl}$, and $\mathrm{S}$ during combustion and co-combustion with wood of high-chlorine biomass in bench and pilot scale fuel beds. Proc. Combust. Instit. 2013, 34, 2363-2372.

17. Wei, X.; Schnell, U.; Hein, K.R.G. Behaviour of gaseous chlorine and alkali metals during biomass thermal utilisation. Fuel 2005, 84, 841-848.

18. Vassilev, S.V.; Baxter, D.; Andersen, L.K.; Vassileva, C.G. An overview of the composition and application of biomass ash: Part 2. Potential utilisation, technological and ecological advantages and challenges. Fuel 2013, 105, 19-39.

19. Kassman, H.; Broström, M.; Berg, M.; Åmand, L.E. Measures to reduce chlorine in deposits: Application in a large-scale circulating fluidised bed boiler firing biomass. Fuel 2011, 90, $1325-1334$.

20. Arvelakis, S.; Folkedahl, B.; Dam-Johansen, K.; Hurley, J. Studying the melting behavior of coal, biomass, and coal/biomass ash using viscosity and heated stage xrd data. Energy Fuels 2006, 20 , 1329-1340.

21. Robinson, A.L.; Junker, H.; Baxter, L.L. Pilot-scale investigation of the influence of coal-biomass cofiring on ash deposition. Energy Fuels 2002, 16, 343-355.

22. Silvennoinen, J.; Hedman, M. Co-firing of agricultural fuels in a full-scale fluidized bed boiler. Fuel Process. Technol. 2013, 105, 11-19.

23. Mroczek, K.; Kalisz, S.; Pronobis, M.; Sołtys, J. The effect of halloysite additive on operation of boilers firing agricultural biomass. Fuel Process. Technol. 2011, 92, 845-855.

24. Wiinikka, H.; Grönberg, C.; Öhrman, O.; Boström, D. Influence of tio2 additive on vaporization of potassium during straw combustion. Energy Fuels 2009, 23, 5367-5374.

25. Lang, T.; Jensen, P.A.; Knudsen, J.N. The effects of ca-based sorbents on sulfur retention in bottom ash from grate-fired annual biomass. Energy Fuels 2006, 20, 796-806.

26. Tobiasen, L.; Skytte, R.; Pedersen, L.S.; Pedersen, S.T.; Lindberg, M.A. Deposit characteristic after injection of additives to a danish straw-fired suspension boiler. Fuel Process. Technol. 2007, 88, 1108-1117.

27. Wang, L.; Hustad, J.E.; Skreiberg, Ø.; Skjevrak, G.; Grønli, M. A Critical Review on Additives to Reduce Ash Related Operation Problems in Biomass Combustion Applications. Energy Procedia 2012, 20, 20-29.

28. Davidsson, K.O.; Åmand, L.E.; Steenari, B.M.; Elled, A.L.; Eskilsson, D.; Leckner, B. Countermeasures against alkali-related problems during combustion of biomass in a circulating fluidized bed boiler. Chem. Eng. Sci. 2008, 63, 5314-5329.

29. Jenkins, B.M.; Baxter, L.L.; Miles, T.R., Jr.; Miles, T.R. Combustion properties of biomass. Fuel Process. Technol. 1998, 54, 17-46.

30. Granada, E.; Patiño, D.; Míguez, J.L.; Morán, J. Analysis of deposition of fouled matter in a water-tube heat exchanger of a biomass combustor. In Proceedingfs of the 34th International Symposium on Combustion, Warsaw, Poland, 29 July-3 August 2012.

31. Febrero, L.; Granada, E.; Pérez, C.; Patiño, D.; Arce, E. Characterisation and comparison of biomass ashes with different thermal histories using tg-dsc. J. Therm. Anal. Calorim. 2014, 118, 1-12. 
32. Rajamma, R.; Ball, R.J.; Tarelho, L.A.C.; Allen, G.C.; Labrincha, J.A.; Ferreira, V.M. Characterisation and use of biomass fly ash in cement-based materials. J. Hazard. Mater. 2009, 172, 1049-1060.

33. Wiinikka, H.; Gebart, R.; Boman, C.; Boström, D.; Öhman, M. Influence of fuel ash composition on high temperature aerosol formation in fixed bed combustion of woody biomass pellets. Fuel 2007, 86, 181-193.

34. Yin, C.; Rosendahl, L.A.; Kær, S.K. Grate-firing of biomass for heat and power production. Progr. Energy Combust. Sci. 2008, 34, 725-754.

35. Porteiro, J.; Patiño, D.; Moran, J.; Granada, E. Study of a fixed-bed biomass combustor: Influential parameters on ignition front propagation using parametric analysis. Energy Fuels 2010, 24, 3890-3897.

36. Wiinikka, H.; Gebart, R. The influence of air distribution rate on particle emissions in fixed bed combustion of biomass. Combust. Sci. Technol. 2005, 177, 1747-1766.

37. Porteiro, J.; Collazo, J.; Patiño, D.; Granada, E.; Gonzalez, J.C.M.; Míguez, J.L. Numerical modeling of a biomass pellet domestic boiler. Energy Fuels 2009, 23, 1067-1075.

38. Shao, Y.; Wang, J.; Preto, F.; Zhu, J.; Xu, C. Ash deposition in biomass combustion or co-firing for power/heat generation. Energies 2012, 5, 5171-5189.

39. Obernberger, I.; Brunner, T.; Bärnthaler, G. Chemical properties of solid biofuels-significance and impact. Biomass Bioenergy 2006, 30, 973-982.

40. Nutalapati, D.; Gupta, R.; Moghtaderi, B.; Wall, T.F. Assessing slagging and fouling during biomass combustion: A thermodynamic approach allowing for alkali/ash reactions. Fuel Process. Technol. 2007, 88, 1044-1052.

(C) 2015 by the authors; licensee MDPI, Basel, Switzerland. This article is an open access article distributed under the terms and conditions of the Creative Commons Attribution license (http://creativecommons.org/licenses/by/4.0/). 